\title{
Software Reliability Modeling using Soft Computing Techniques: Critical Review
}

\author{
Kuldeep Singh Kaswan \\ Research Scholar, Department of Computer Science, Banasthali University, Banasthali, Rajasthan, India \\ E-mail: kaswankuldeep@gmail.com \\ Sunita Choudhary \\ Department of Computer Science, Banasthali University (Rajasthan) \\ E-mail: sunitaburdak@yahoo.co.in \\ Kapil Sharma \\ Department of Computer Science \& Engineering, Delhi Technological University (Delhi) \\ E-mail: kapil@ieee.org
}

\begin{abstract}
Software reliability models assess the reliability by predicting faults for the software. Reliability is a real world phenomenon with many associated real-time problems. To obtain solutions to problems quickly, accurately and acceptably, a large number of soft computing techniques have been developed, but it is very difficult to find out which one is the most suitable and can be used globally. In this paper, we have provided an overview of existing soft computing techniques, and then critically analyzed the work done by the various researchers in the field of software reliability. Further to this, we have also compared soft computing techniques in terms of software reliability modeling capabilities.
\end{abstract}

Index Terms- Neural Network, Fuzzy Logic, Genetic Programming, Cuckoo Search, Soft Computing And Software Reliability.

\section{INTRODUCTION}

Software engineering is a discipline whose aim is the production of quality software, that is delivered on time, within budget, and that satisfies its requirements [1]. Software Engineering plays a significant role in software life because there is always a need of high quality. Software reliability is the most measurable aspect of its quality.

Software reliability can be defined as the probability of failure-free operation for a specified period of time in a specified environment [2] [3] [4]. The software failures are introduced by the system analysts, designers, programmers and managers during different phases of software development life cycle. To detect and remove these errors, the software system is tested. The quality of software system in terms of reliability is measured by the removal of these errors.

Software reliability modeling plays a significant role in many critical and daily life applications that has led to the tremendous work being carried out in modeling process. These models successfully have been used for estimation and prediction of errors remaining in the software. User can access the current and future reliability through testing using these models, as well as make decisions about the software such as whether the product is released in its present state or require further testing in order to improve the quality of software.

Soft computing techniques are the collection of different concepts and techniques that aim to overcome the difficulties encountered in real world problems. It deals with the problems that seem to be imprecise, uncertain and difficult to categorize. One may see soft computing as an attempt to mimic natural creatures: plants, animals, human beings, that are soft, flexible, adaptive and clever. In this sense soft computing is the name of a family of problem-solving methods that have analogy with biological reasoning and problem solving.

This paper is further organized as follows: section II includes different soft computing techniques. In section III we discuss the role of these soft computing techniques in software reliability models. Section IV contains description of soft computing technique in software reliability models. Comparison of these soft computing techniques in terms of modeling capabilities is given in section V. Finally, the paper concludes with section VI.

\section{SOFT-COMPUTING TECHNIQUES}

Soft computing is an association of computing methodologies that includes as its principal members' fuzzy logic, chaos theory, neuro-computing, evolutionary computing and probabilistic computing [5]. Soft computing is based on natural as well as artificial ideas. It is referred as a computational intelligence [6].

There are a number of soft computing techniques that plays an important role in many fields such as, in computer science, machine learning, artificial intelligence applied in engineering such as mobile robot, cooling heating, communication network, inverters, converters, electric power system, power electronics, motion control and aircraft etc. In this section, we discussed about the different classification schemes of existing soft computing techniques as shown in Figure-1. 


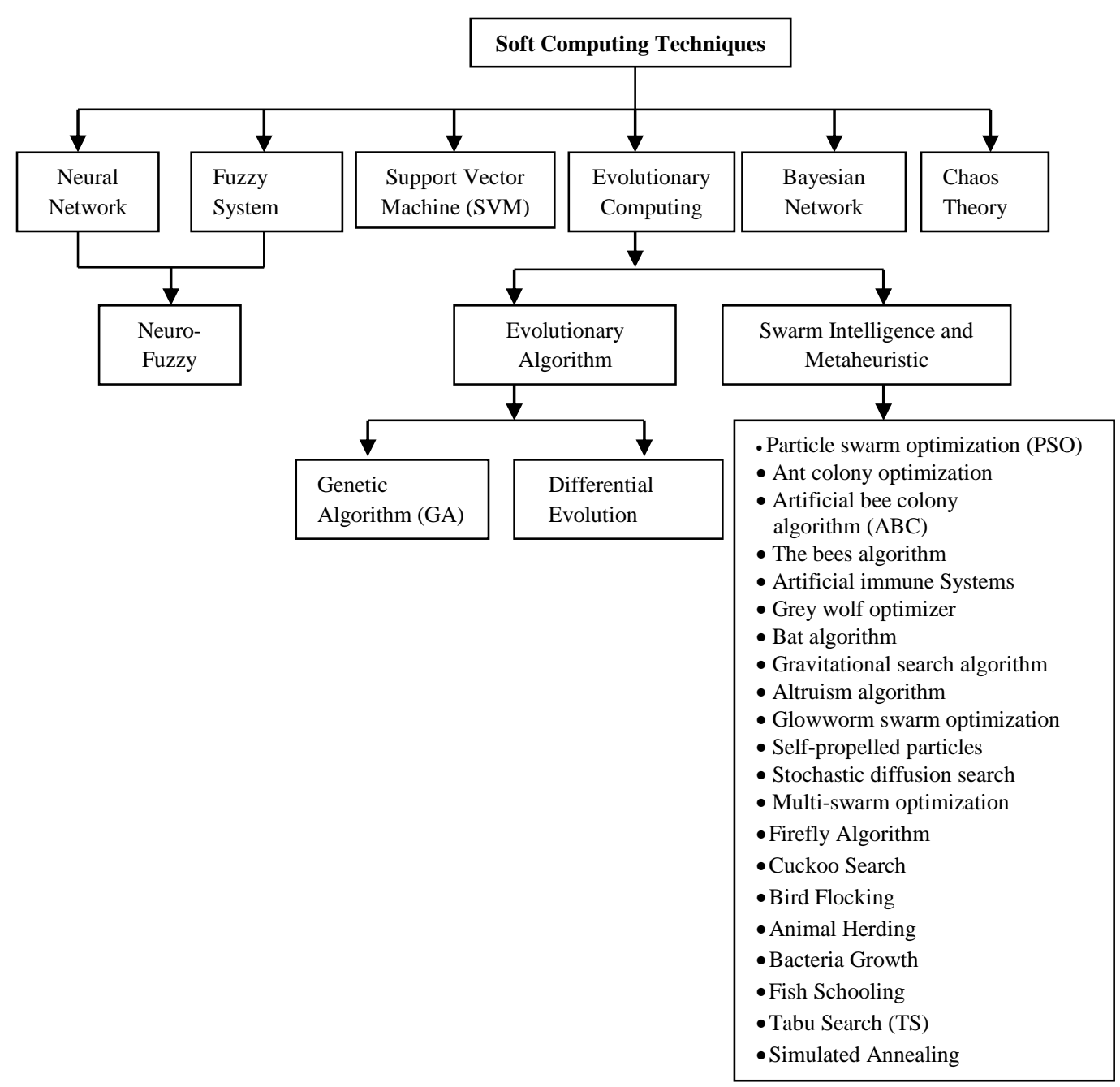

Fig. 1. Soft Computing Techniques

In figure-1 we discussed about some soft computing techniques as neural networks, Fuzzy Logic, Support vector machine (SVM), Evolutionary computing, Bayesian Network and Chaos Theory. Then some techniques are also used in the combination with the others as Neuro-Fuzzy, the combination of Neural Network and Fuzzy Logic. Evolutionary Computing System is further divided into Evolutionary Algorithm and Swarm Intelligence techniques.

\section{- Neural Networks}

According to Nigrin, A. (1993) neural network is a circuit composed of a very large number of simple processing elements that are neurally based. Each element operates asynchronously, on local information; thus there is no overall system clock. Applications of neural networks are character recognition, image compression, stock market prediction, traveling salesman's problem, medicine, electronic nose, loan applications and security.

\section{- Support Vector Machine}

Boser, Guyon, and Vapnik developed Support Vector Machine (SVM) was in 1992, introduced, in COLT-92. Support vector machines (SVMs) are a set of related supervised learning methods used for classification and regression. Support vector machines (SVM) have both a solid mathematical background and good performance in practical applications, such as image processing, artificial intelligence, medical, pattern recognition, machine learning, applied statistics, business intelligence, and information technology.

\section{- Fuzzy logic}

Developed by Lotfi A. Zadeh in 1965, at the University of California in Berkeley. It is a multi-valued logic that allows intermediate values to be defined between conventional evaluations like true/false, yes/no and low/high, etc. [7] [ 8]. The most significant application area of fuzzy logic has been in control field. Fuzzy control having been successfully applied to numerous problems, these includes fans control, complex aircraft engines and control surfaces, wheel slip control, helicopter control, automatic transmission, industrial and missile guidance.

\section{- Evolutionary Computing}

Evolutionary computing can be viewed as an adaptation of a probabilistic approach based on principles of natural evolution [9]. It can also defined as the stochastic search and optimization heuristic approach derived from the classic evolution theory, that are 
implemented on computers usually [10]. Evolutionary algorithms have been successfully applied to numerous problems from different domains, bioinformatics, including optimization, automatic programming, signal processing, social systems [11].

\section{- Bayesian Network}

Bayesian networks are graphical models for reasoning under uncertainty, where the nodes represent variables (discrete or continuous) and arcs represent direct connections between them. various applications such as the impact of management style on statistical efficiency, studies of web site usability, operational risks, biotechnology, customer satisfaction surveys, health-care systems and the testing of web services.

\section{- Chaos Theory}

A deterministic system is said to be chaotic whenever its evolution sensitively depends on the initial conditions. This property implies that two trajectories emerging from two different closes by initial conditions separate exponentially in the course of time. The necessary requirements for a deterministic system to be chaotic are that the system must be nonlinear, and be at least three dimensional [12].

Each soft computing technique can be used separately, but its complementary nature is its more powerful advantage. We can also create a hybrid system, combination of hard and soft computing, that produce solutions to problems that are too complex or inherently noisy to tackle with conventional mathematical methods.

\section{Potential USAGES OF SOFT COMPUTING TECHNIQUES IN SOFTWARE RELIABILITY MODELING}

Soft computing techniques can be used for software faults diagnosis, reliability optimization and for time series prediction during the software reliability analysis. In this section, we discussed about the applications of soft computing technologies in software reliability modeling.

\section{- Neural Networks}

Neural networks are simplified model of the biologic neuron system, it is massively parallel distributed processing system made up of highly interconnected neural computing elements that have the ability to learn and thereby acquire knowledge and make it available for use. Neural network has been applied for parameters estimation of the formal model and self learning process in order to predict the future outcomes. It has been shown that feed forward network can be applied for prediction. Back-error propagation is one of the most widely used neural network paradigms and has been applied successfully in a broad range of areas [13].

Karunanithi et al. [14] [15] predict cumulative number of failure by design first neural network based software reliability model. They used feed-forward neural network, recurrent neural network and Elman neural network in their study and use execution time as the input of the network. They found that their models are better prediction models than some other statistical models [16] Used connectionist models for software reliability prediction. Design the architecture of neural network by Falman's cascade correlation algorithm. They found that for end point prediction connectionist approach.

Khoshgoftaar et al. [17] used the neural network for predicting the number of faults and introduced an approach for static reliability modeling. Then trained two neural networks; one with the complete set of principal components and one with the set of components selected by multiple regression model selection. Comparison of these models showed a better understanding of neural network software quality models.

Sitte [18] compared, purposed neural network based software reliability prediction model, with recalibration for parametric models using some meaningful predictive measures with same datasets. Result showed that prediction with the help of neural network approach is better than others.

Cai et al. [19] presented neural network based method for software reliability predictions, used back propagation algorithm for training. Performance of this purposed approach is evaluated by using different number of input nodes and hidden nodes. Result showed that its performance depends upon the nature of the handled data sets.

Ho et al. [20] investigated a modified Elman recurrent neural network in modeling and predicting software failures and then performed a comprehensive study of connectionist models and their applicability to software reliability prediction and found them to be better and more flexible than the traditional models.

Tian and Noore [21] proposed an on-line adaptive software reliability prediction model using evolutionary connectionist approach based on multiple-delayed-input single-output architecture, which showed better performance with respect to next-step predictability compared to existing NN model.

Tian and Noore [22] presented an evolutionary neural network based method for software reliability prediction, used multiple-delayed-input single output architecture. Result showed that neural network architecture has a great impact on the performance of the network.

Yu Shen Su et al. [23] purposed a model that uses the neural network approach to build a dynamic weighted combinational model. Then compared the performances of the neural network models with some conventional SRGMs from three aspects: goodness of fit, prediction ability for short-term prediction and long-term prediction. Result shows that purposed model has more accuracy with both goodness of fit and the prediction ability compared to existing conventional models.

Viswanath [24] proposed two models such as neural network based exponential encoding and neural network based logarithmic encoding for prediction of cumulative number of failures in software. It takes execution time as the input and applied on four data sets. Result showed that its result is better that other statistical model.

$\mathrm{Hu}$ et al. [25] proposed an artificial neural network model to improve the early reliability prediction for 
current projects/releases by reusing the failure data from past projects/releases. Better prediction performance is observed in early phase of testing compared with original ANN model without failure data reuse.

$\mathrm{Su}$ and Huang [26] proposed an artificial neuralnetwork-based approach for software reliability estimation and modeling then further use of the neural network approach to build a dynamic weighted combinational model. The results obtained from the experiments show that the proposed model has a fairly accurate prediction capability

Kanmani et al. [27] purposed two neural network based software fault prediction models using ObjectOriented metrics. The results are compared with two statistical models using five quality attributes and found that neural networks do better

Aljahdali et al. [28] explored connectionist artificial neural networks model as an alternative approach to derive these models by investigating the performance analysis of four different connectionist paradigms, multilayer perceptron neural network, radial-basis functions, Elman recurrent neural networks and a neuro-fuzzy model, for modeling the software reliability prediction

In [29] [30] Singh et al. used feed forward neural network for software reliability prediction and applied back propagation algorithm to predict software reliability growth trend. Also demonstrated a comparative analysis between the proposed approach and three well known software reliability growth prediction models using seven different failure datasets collected from standard software projects to test the validity of the presented method.

Nirvikar Katiyar et al. [31] developed a non-parametric software reliability prediction system based on the neural network effects to improve the predictability by utilizing the diversity among the combined component neural networks

Huang et al. [32] derived software reliability growth model (SRGM) based on non-homogeneous poison processes (NHPP) using a unified theory by incorporating the concept of multiple change-points into software reliability modeling.

Manjubala Bisi et al. [33] proposed a neural network based software reliability model to predict the cumulative number of failures based on Feed Forward architecture. The effect of encoding and the effect of different encoding parameter on prediction accuracy have been studied and its performance is tested using eighteen software failure data sets.

Sandeep Kumar Jain et al. [34] proposed a method to estimate the reliability of the software consisting of components by using different neural network architectures. Then estimate the faults prediction behavior in the set of components over a cumulative execution time interval besides this the prediction of faults is estimated for the complete software. To predict the faults in each component of the software with the prediction of faults for the complete software for given cumulative execution time, apply the feed forward neural network architectures \& its generalization capability.

\section{- Fuzzy System}

Fuzzy Logic is derived from fuzzy set theory dealing with reasoning that is appropriate rather than precisely deduced from classical predicate logic. A fuzzy model is a mapping between linguistic terms, attached to variables. Therefore the input to and output from a fuzzy model can be either numerical or linguistic [35].

Cai et al. [36] discussed the development of fuzzy software reliability models in place of probabilistic software reliability models (PSRMs). It was based on the proof that software reliability is fuzzy in nature. A demonstration of how to develop a fuzzy model to characterize software reliability was also presented.

Khalaf khatatneh [37] developed a software reliability prediction model. It was implemented using fuzzy logic. This model focused on a particular dataset behavior in predicting reliability. Focusing on a particular dataset behavior is performed to develop an accurate model since the recent work focused on developing a model which can be more accurate.

Reformat [38] proposed an approach leading to a multi technique knowledge extraction and development of a comprehensive meta-model prediction system in the area of corrective maintenance of software. The system was based on evidence theory and a number of fuzzy-based models.

Sultan Aljahdali et al. [39] investigated the use of fuzzy logic on building SRGM to estimate the expected software faults during testing process. Purposed model consists of a collection of linear sub-models, based on the Takagi-Sugeno technique and attached efficiently using fuzzy membership functions to represent the expected software faults as a function of historical measured faults. This purposed model gives a high performance modeling capabilities.

S. Chatterjee et al. [40] two fuzzy time series based software reliability models have been proposed. The first one predicts the time between failures of software and the second one predicts the number of errors present in software. The purposed models are flexible, assumption free and very simple in computation. It not required any de-fuzzication techniques separately, which results in a significant reduction of computation time.

\section{- Neuro-Fuzzy System}

Neuro-fuzzy system combines the features of fuzzy logic and neural networks. It can be used for software reliability modeling investigation. Neuro-fuzzy describes a methodology for controlling neural networks by fuzzy logic.

Kirti Tyagi et al. [41] proposed a model for estimating CBSS reliability, known as an adaptive neuro fuzzy inference system (ANFIS) that is based on these two basic elements of soft computing, neural network and fuzzy logic. ANFIS model gives a more accurate measure of reliability than the FIS model, as it reduces error from $11.74 \%$, in case of FIS model, to $6.66 \%$ in ANFIS.

\section{- Genetic Algorithm (GA)}

Genetic algorithm is a model of machine learning which derives its behavior from a metaphor of the 
process of evolution in nature. This is done by the creation within a machine of a population of individuals represented by chromosomes.

The fitness of each chromosome is determined by evaluating it against an objective function. To simulate the natural survival of the fittest process, best chromosomes exchange information to produce offspring chromosomes. The offspring solutions are then evaluated and used to evolve the population if they provide better solutions than weak populations members. Usually, the process is continued for a large number of generations to obtain a best-fit solution.

Liang et al. [42] [43] proposed a genetic algorithm optimizing the number of delayed input neurons and the number of neurons in the hidden layer of the neural network, predicting software reliability and software failure time.

Sultan H. Aljahdali et al. [44] [45] explored Genetic Algorithms (GA) as an alternative approach to derive software reliability models. For purposed system applicability three study sets; Military, Real Time Control and Operating System were used.

Satya Prasad R. et al. [46] incorporate both imperfect debugging and change-point problem into the software reliability growth model (SRGM) based on the wellknown exponential distribution the parameter estimation is studied. Proposed model is rated as better than the other considered models with respect to all the conditions are chosen.

\section{- Genetic Programming (GP)}

Genetic programming can be viewed as an extension of the genetic algorithm, a model for testing and selecting the best choice among a set of results, each represented by a string. Genetic programming goes a step farther and makes the program or "function" the unit that is tested. Two approaches are used to select the successful program - cross-breeding and the tournament or competition approach. A difficult part of using genetic programming is determining the fitness function, the degree to which a program is helping to arrive at the desired goal.

E. Costa et al. [47] Modeling software reliability growth with genetic programming. Experiments conducted to confirm the purposed hypothesis and demonstrate better results as compared to other traditional models and neural network model.

E. Oliveira et al. [48] improve software reliability models using boosting techniques based on genetic programming. Boosting Technique combines several hypotheses of the training set to get better results. The most important improvement of this work is when consider models based on time and got excellent results by using just one function set.

Y. Zhang et al. [49] Predicting for MTBF failure data series of software reliability by genetic programming algorithm. The evolution model of GP is then analyzed and appraised according to five characteristics criteria for some common-used software testing cases. Result showed the higher prediction precision and better applicability.
Wasif Afzal et al. [50] discussed the suitability of using GP for software reliability growth modeling and highlight the mechanisms that enable GP to progressively search for fitter solutions. The experiments of using GP for software reliability growth modeling have indicated positive results

Eduardo Oliveira Costa et al. [51] introduced a new GP based approach, named $(\mu+\lambda)$ GP. This algorithm was introduced to improve the performance of GP. To evaluate this purposed algorithm, two kinds of models: based on time and on coverage were presented for experimental results, which is always better than classical GP.

Zainab Al-Rahamneh et al. [52] proposed the use of Genetic Programming (GP) as an evolutionary computation approach to handle the software reliability modeling problem. Evaluate the GP developed model and results show that this purposed model is superior to other models such as Yamada S-shaped, Generalized Poisson, NHHP and Schneidewind reliability models.

\section{- Artificial Bee Colony (ABC)}

Dervis Karaboga, in 2005, defined a new algorithm, motivated by the intelligent behavior of honey bees known as artificial bee colony. It is an optimized tool provides a population-based search procedure in which inviduals called foods positions are modified by the artificial bees with time and bee's aim to discover the places of food sources with high nectar amount and finally the one with highest nectar.

Tarun Kumar Sharma et al. [53] proposed a modified version of the $\mathrm{ABC}$, the DABC (Dichotomous $\mathrm{ABC}$ ), to improve its performance, in terms of converging to individual optimal point and to compensate the limited amount of search moves of original ABC. Also explored the applicability of the modified artificial bee colony algorithm to estimate the parameters of software reliability growth models (SRGM). The estimated model parameters were used to predict the faults in a software system during the testing process.

\section{- Ant Colony}

Ant Colony Optimization [54] is a technique which uses probability to solve problems where the computations are reduced with the help of graphs to get efficient paths. It has been applied to many fields as its robustness and is easy to collaborate with other methods. It has well performance to the optimization problem and has a good convergence rate.

Changyou Zhenga et al. [55] proposed a parameter estimation method based on the Ant Colony Algorithm. Its results are derived from Numerical examples based on three sets of real failure data. Purposed method shows higher precision and faster convergence speed.

Latha Shanmugam et al. [56] discussed a parameter estimation method based on Ant Colony Algorithm. The outcome of the experiment using six typical models demonstrated that this algorithm can be applied for estimating parameters. Higher precision and faster convergence speed is achieved through this method when compared with PSO algorithm 
Latha Shanmugam et al. [57] studied enhancement and Comparison of Ant Colony Optimization Methods for Software Reliability Models. The Enhanced method shows significant advantages in finding the goodness of fit for software reliability model such as finite and infinite failure Poisson model and binomial models. It is comparatively giving better Estimation Accuracy (approximately 10\%) than the existing Ant Colony Optimization.

\section{- Simulated Annealing (SA) Algorithm}

Simulated annealing (SA) is an iterative search method inspired by the annealing of metals $[58,59]$ Starting with an initial solution and armed with adequate perturbation and evaluation functions, the algorithm performs a stochastic partial search of the state space

Nidhi Gupta et al. [60] the simulated annealing technique of mean field approximation for finding the possible minimum number of failed components in the sequential testing. These minimum numbers of failed components are depending upon the selection of time intervals or slots. Also purposed a new energy function with the mean field approximation. The algorithm of the whole process shows that this approach can generate the optimal solution.

Pai and Hong [61] applied support vector machines (SVMs) for forecasting software reliability where simulated annealing (SA) algorithm was used to select the parameters of the SVM model. The experimental results reveal that the SVM model with simulated annealing algorithms (SVMSA) results in better predictions than the other methods.

Mohamed Benaddy at al. [62] presented a hybrid approach based on the Neural Networks and Simulated Annealing. An adaptive simulated Annealing algorithm is used to optimize the mean square of the error produced by training the neural network, predicting software cumulative failure. The purposed adaptive Simulated Annealing gives better performance in execution time than the Real Coded Genetic Algorithm (RCGA), because of the search space, which reduced from a population of solutions for the RCGA to one solution for the proposed Simulated Annealing.

\section{- Tabu Search Algorithm}

The Tabu Search (TS) is an optimization method, based on the premise that problem solving, in order to qualify as intelligent, and must incorporate adaptive memory and responsive exploration [63]. The Tabu method was partly motivated by the observation that human behavior appears to operate with a random element that leads to inconsistent behavior given similar circumstances.

M. Caserta et al. [64] presented a new meta- heuristicbased algorithm for complex reliability problems. The algorithm effectively uses features of the Tabu Search paradigm, with special emphasis on the exploitation of memory-based mechanisms. It balances intensification with diversification via the use of short-term and longterm memory. The proposed algorithm proves to be robust with respect to its parameters and it is especially suited for very large scale instances of the reliability problem, when exact approaches are doomed to fail.

\section{- Cuckoo Search Algorithm}

This algorithm is based on the obligate brood parasitic behavior of some cuckoo species in combination with the L'evy flight behavior of some birds and fruit flies. Cuckoo search algorithm is very successful in finding good and acceptable solutions to the problem of parameter estimation of Software Reliability Growth Models. This algorithm search strategy can efficiently navigate throughout the search space of the problem and locate very good solutions using fewer iterations and smaller populations.

Najla Akram AL-Saati et al. [65] estimated parameters based on the available failure data. Cuckoo Search outperformed both PSO and ACO in finding better parameters tested using identical datasets, but worse in case of extended ACO. the Exponential, Power, SShaped, and M-O models are considered in this work. The search strategy of the cuckoo can efficiently navigate throughout the search space of the problem and locate very good solutions using fewer iterations and smaller populations

\section{SUMMARIZATION}

In the past few decades a number of software reliability models have been analyzed, designed and evaluated. Soft computing played an important role in the recent advancements in the software reliability growth models. These models included the application of different soft computing techniques such as Neural Network (NN), Fuzzy Logic, Genetic Algorithms (GA), Genetic Programming (GP), Artificial Bee Colony (ABC) and Ant Colony etc., a brief summary of soft computing techniques in software reliability models has been summarized in this section as shown in table-1.

Table 1. Summary of Soft Computing Techniques in Software Reliability Models

\begin{tabular}{|c|c|c|c|c|}
\hline $\begin{array}{c}\text { Sr. } \\
\text { No. }\end{array}$ & Study & $\begin{array}{c}\text { Technology } \\
\text { Used }\end{array}$ & Project Data & Summary of Result \\
\hline 1 & $\begin{array}{c}\text { N. Karunanithi, Y.K. } \\
\text { Malaiya and D. } \\
\text { Whitley }\end{array}$ & $\begin{array}{c}\text { Neural } \\
\text { Network }\end{array}$ & $\begin{array}{c}\text { DS-1 K. Matsumoto (1988) } \\
\text { DS-2 J. D. Musa (1987) } \\
\text { DS-3 M. Ohba (1984) }\end{array}$ & $\begin{array}{c}\text { Explores the use of feed-forward neural networks } \\
\text { as a model for software reliability growth } \\
\text { prediction }\end{array}$ \\
\hline 2 & $\begin{array}{c}\text { N. Karunanithi, D. } \\
\text { Whitley, Y.K. } \\
\text { Malaiya }\end{array}$ & $\begin{array}{c}\text { Neural } \\
\text { Network }\end{array}$ & $\begin{array}{c}\text { DS form Yoshiro Tohma } \\
\text { project }\end{array}$ & $\begin{array}{c}\text { After training the neural network with a failure } \\
\text { history up to time } t \text { you can use the network to } \\
\text { predict the cumulative faults at the end of a } \\
\text { future testing and debugging session. }\end{array}$ \\
\hline
\end{tabular}




\begin{tabular}{|c|c|c|c|c|c|}
\hline 3 & $\begin{array}{l}\text { Taghi M. } \\
\text { Khoshgoftaar, Robert } \\
\text { M. Szabo and Peter J. } \\
\quad \text { Guasti }\end{array}$ & $\begin{array}{l}\text { Neural } \\
\text { Network }\end{array}$ & $\begin{array}{l}\text { Data collected from three } \\
\text { similar systems }\left(\text { Kernel }_{2},\right. \\
\text { Kernel }_{3} \text { and } \\
\left.\text { Kernel }_{4}\right) \text { and two dissimilar } \\
{\text { systems }\left(\text { Kernel }_{5} \text { and }\right.}^{\left.\text {Kernel }_{6}\right)}\end{array}$ & $\begin{array}{l}\text { The excellent predictive results observed in the } \\
\text { neural network models indicate that neural } \\
\text { networks should be seriously considered as an } \\
\text { effective modeling tool for software engineers }\end{array}$ & [17] \\
\hline 4 & Renate Sitte & $\begin{array}{l}\text { Neural } \\
\text { Network }\end{array}$ & Musa data-sets S1 \& SS3 & $\begin{array}{l}\text { Neural Networks are not only much simpler to } \\
\text { use than the recalibration method, but that they } \\
\text { are equal or better trend predictors }\end{array}$ & [18] \\
\hline 5 & $\begin{array}{l}\text { S. L. Ho, M. Xie and } \\
\text { T. N. Goh }\end{array}$ & $\begin{array}{l}\text { Neural } \\
\text { Network }\end{array}$ & $\begin{array}{l}\text { DS-1: Military computer } \\
\text { system } \\
\text { DS-2: Musa-Okumoto } \\
\text { Model } \\
\text { DS-3: Goel Okumoto } \\
\text { Model }\end{array}$ & $\begin{array}{l}\text { The Elman model is comparatively better than } \\
\text { the Jordan model and very much superior than } \\
\text { the feed -forward model }\end{array}$ & [20] \\
\hline 6 & $\begin{array}{l}\text { Nirvikar Katiyar and } \\
\text { Raghuraj Singh }\end{array}$ & $\begin{array}{l}\text { Neural } \\
\text { Network }\end{array}$ & $\begin{array}{l}\text { DS1 and DS2 from } \\
\text { handbook of software } \\
\text { reliability engg. Lyu M.R. } \\
\text { (1996) New York }\end{array}$ & $\begin{array}{l}\text { Purposed system achieves significantly lower } \\
\text { prediction error compared with the single NN } \\
\text { and traditional SRGMs }\end{array}$ & [31] \\
\hline 7 & Sultan Aljahdali et al. & $\begin{array}{l}\text { Neural } \\
\text { Network }\end{array}$ & $\begin{array}{l}\text { Real -time command and } \\
\text { Control project Word } \\
\text { processing Commericial } \\
\text { and military applications }\end{array}$ & $\begin{array}{l}\text { NN provide models with smaller normalized root } \\
\text { of mean of the square of error than the regression } \\
\text { model in all considered cases }\end{array}$ & [] \\
\hline 8 & $\begin{array}{l}\text { Yu Shen Su, Chin- } \\
\text { Yu Huang, Yi Shin } \\
\text { Chen and Jing Xun } \\
\text { Chen }\end{array}$ & $\begin{array}{l}\text { Neural } \\
\text { Network }\end{array}$ & $\begin{array}{l}\text { Real command \& control } \\
\text { project, John D Musa, Bell } \\
\text { Lab. }\end{array}$ & $\begin{array}{l}\text { Achieve a dynamic weighted combinational } \\
\text { model }\end{array}$ & [23] \\
\hline 9 & $\begin{array}{l}\text { Sultan H. Aljahdali } \\
\text { and Khalid A. } \\
\text { Buragga }\end{array}$ & $\begin{array}{l}\text { Neural } \\
\text { Network }\end{array}$ & Rea 1 time control project & $\begin{array}{l}\text { The Elman recurrent NNs is a robust technique } \\
\text { for function prediction due capturing the } \\
\text { dynamic behavior of the data set. }\end{array}$ & [28] \\
\hline 10 & Manjubala Bisi et al. & $\begin{array}{l}\text { Neural } \\
\text { Network }\end{array}$ & $\begin{array}{l}18 \text { different data sets } \\
\text { (Military, Real time } \\
\text { System, Real time } \\
\text { Command and Control, } \\
\text { On-line data Entry etc.) }\end{array}$ & $\begin{array}{l}\text { A Feed Forward neural network with two } \\
\text { encoding scheme such as exponential and } \\
\text { logarithmic function has been proposed. }\end{array}$ & [33] \\
\hline 11 & $\begin{array}{l}\text { Sandeep Kumar Jain } \\
\text { \& Manu Pratap Singh }\end{array}$ & $\begin{array}{l}\text { Neural } \\
\text { Network }\end{array}$ & $\begin{array}{l}\text { Data collected from local } \\
\text { training set }\end{array}$ & $\begin{array}{l}\text { Estimated the faults prediction behavior in the set } \\
\text { of components over a cumulative execution time } \\
\text { interval besides this the prediction of faults is } \\
\text { estimated for the complete software. }\end{array}$ & [34] \\
\hline 12 & $\begin{array}{l}\text { S. Chatterjee, S. } \\
\text { Nigam, J.B. Singh, } \\
\text { L.N. Upadhyaya }\end{array}$ & Fuzy Logic & $\begin{array}{l}\text { DS-1: Musa J D(1975) } \\
\text { software reliability data } \\
\text { DS-2: Pham H(2006) } \\
\text { system software reliability }\end{array}$ & $\begin{array}{l}\text { Purposed models are flexible, assumption free } \\
\text { and very simple in computation. It not required } \\
\text { any de-fuzzified techniques separately and } \\
\text { computation time is reduced }\end{array}$ & [40] \\
\hline 13 & Sultan Aljahdali & Fuzzy Logic & $\begin{array}{l}\text { Real command \& control } \\
\text { project, Military and } \\
\text { operating system, John D } \\
\text { Musa, Bell lab. }\end{array}$ & $\begin{array}{l}\text { Developed models provide high performance } \\
\text { modeling capabilities. }\end{array}$ & [39] \\
\hline 14 & $\begin{array}{l}\text { Khalaf Khatatneh and } \\
\text { Thaer Mustafa }\end{array}$ & Fuzzy Logic & $\begin{array}{l}\text { dataset from command and } \\
\text { control applications, Musa, } \\
\text { John D. }\end{array}$ & $\begin{array}{l}\text { Developed model can predict accurate results in } \\
\text { most points of the target database }\end{array}$ & [37] \\
\hline 15 & $\begin{array}{l}\text { Sultan H. Aljahdali } \\
\text { and Mohammed E. } \\
\text { El-Telbany }\end{array}$ & $\begin{array}{l}\text { Genetic } \\
\text { Algorithm }\end{array}$ & $\begin{array}{l}\text { Data from three projects } \\
\text { Military, Real System } \\
\text { Control and Operating } \\
\text { system }\end{array}$ & $\begin{array}{l}\text { Measured the predictability of software reliability } \\
\text { using ensemble of models which performed } \\
\text { better than the single model and also find that the } \\
\text { weighted average combining method for } \\
\text { ensemble has a better performance in a } \\
\text { comparison with average method }\end{array}$ & [44] \\
\hline 16 & $\begin{array}{l}\text { Sona Ahuja, Guru Sa } \\
\text { ran Mishra and Agam } \\
\text { Prasad Tyagi }\end{array}$ & $\begin{array}{l}\text { Genetic } \\
\text { Algorithm }\end{array}$ & $\begin{array}{l}\text { Musa Data-set, software } \\
\text { reliability prediction and } \\
\quad \text { application, } 1985\end{array}$ & $\begin{array}{c}\text { GA based hybrid stochastic search technique, has } \\
\text { turned out to be good tool for optimized } \\
\text { simulated trajectory for variable which are } \\
\text { important performance indicator to predict } \\
\text { quality of reliability of the predicted software } \\
\text { failure }\end{array}$ & [66] \\
\hline 17 & $\begin{array}{l}\text { Sultan H. Aljahdali } \\
\text { and Mohammed E. }\end{array}$ & $\begin{array}{l}\text { Genetic } \\
\text { Algorithm }\end{array}$ & $\begin{array}{l}\text { Data from three projects. } \\
\text { They are Military, Real } \\
\text { Time Control and Operating } \\
\text { System. }\end{array}$ & $\begin{array}{l}\text { As far as the predictability of the single AR } \\
\text { model and ensemble of AR models trained by } \\
\text { GA algorithm over the trained and test data is } \\
\text { concerned, the ensemble of models performed } \\
\text { better than the single model. Also, find that the } \\
\text { weighted average combining method for } \\
\text { ensemble has a better performance in a } \\
\text { comparison with average method. }\end{array}$ & [45] \\
\hline
\end{tabular}




\begin{tabular}{|c|c|c|c|c|c|}
\hline 18 & $\begin{array}{l}\text { R.Satya Prasad, } \\
\text { O.Naga Raju and } \\
\text { R.R.L Kantam }\end{array}$ & $\begin{array}{l}\text { Genetic } \\
\text { Algorithm }\end{array}$ & $\begin{array}{l}\text { DS-1: Misra, P.N., } 1983 . \\
\text { Software reliability } \\
\text { analysis. IBM Syst. } \\
\text { DS-2: Pham, H., } 1993 . \\
\text { Software reliability } \\
\text { assessment: Imperfect } \\
\text { debugging and multiple } \\
\text { failure types in software } \\
\text { development }\end{array}$ & $\begin{array}{l}\text { This model is rated as better than the other } \\
\text { considers models with respect to all conditions } \\
\text { are chosen. }\end{array}$ & [46] \\
\hline 19 & $\begin{array}{l}\text { Eduardo Oliveira } \\
\text { Costa et al. }\end{array}$ & $\begin{array}{l}\text { Genetic } \\
\text { Programming }\end{array}$ & $\begin{array}{l}\text { DS-1 John Musa at Bell } \\
\text { Telephone Laboratories } \\
\text { DS-2 failure data of a } \\
\text { program called Space }\end{array}$ & $\begin{array}{l}\text { GP is a suitable tool to discover an equation to } \\
\text { modeling software reliability and is also able to } \\
\text { discover the equation that better represents the } \\
\text { data }\end{array}$ & [47] \\
\hline 20 & $\begin{array}{l}\text { E. Oliveira, A. Pozo, } \\
\text { and S. Vergilio }\end{array}$ & $\begin{array}{l}\text { Genetic } \\
\text { Programming }\end{array}$ & $\begin{array}{c}\text { DS-1 John Musa } \\
\text { at Bell Telephone } \\
\text { Laboratories } \\
\text { DS-2 failure data } \\
\text { of a program called Space }\end{array}$ & $\begin{array}{l}\text { Use boosting techniques to improve software } \\
\text { reliability models based on Genetic } \\
\text { Programming. }\end{array}$ & [48] \\
\hline 21 & $\begin{array}{l}\text { Wasif Afzal and } \\
\text { Richard Torkar }\end{array}$ & $\begin{array}{l}\text { Genetic } \\
\text { Programming }\end{array}$ & $\begin{array}{l}\text { Data available at: } \\
\text { http://www.gp-field- } \\
\text { guide.org.uk, } 2008 \text {. }\end{array}$ & $\begin{array}{l}\text { The experiments of using GP for software } \\
\text { reliability growth modeling have indicated } \\
\text { positive results, which warrant further } \\
\text { investigation with larger real-world industrial } \\
\text { data sets. }\end{array}$ & [50] \\
\hline 22 & $\begin{array}{l}\text { Eduardo Oliveira } \\
\text { Costa, Aurora } \\
\text { Trinidad Ramirez } \\
\text { Pozo, and Silvia } \\
\text { Regina Vergilio }\end{array}$ & $\begin{array}{l}\text { Genetic } \\
\text { Programming }\end{array}$ & $\begin{array}{l}\text { DS-1: software reliability } \\
\text { data by J Musa(1980) } \\
\text { DS-2: space program }\end{array}$ & $\begin{array}{l}\text { Purposed }(\mu+\lambda) \text { GP system results are always } \\
\text { better than the classical technique results also } \\
\text { improves the performance for small datasets }\end{array}$ & [51] \\
\hline 23 & $\begin{array}{c}\text { Zainab Al- } \\
\text { Rahamneh, } \\
\text { Mohammad Reyalat, } \\
\text { Alaa F. Sheta, } \\
\text { Sulieman Bani- } \\
\text { Ahmad, Saleh Al- } \\
\text { Oqeili }\end{array}$ & $\begin{array}{c}\text { Genetic } \\
\text { Programming }\end{array}$ & $\begin{array}{l}\text { Data set from Y. Tohma } \\
\text { published in IEEE } \\
\text { transactions on Software } \\
\text { Engineering, Vol. 15, No. 3, } \\
1989\end{array}$ & $\begin{array}{l}\text { Here adopted recalibrated and adjusted GP } \\
\text { operators to speed up the convergence process }\end{array}$ & [52] \\
\hline 24 & $\begin{array}{c}\text { Tarun Kumar } \\
\text { Sharma, Millie Pant } \\
\text { and Ajith Abraham }\end{array}$ & $\begin{array}{l}\text { Artificial Bee } \\
\text { Colony }\end{array}$ & $\begin{array}{c}\text { IEEE Congress on } \\
\text { Evolutionary Computation, } \\
\text { Sheraton, Vancouver Wall } \\
\text { Centre, Vancouver, BC, } \\
\text { Canada, 2006., 10428- } \\
10435\end{array}$ & $\begin{array}{c}\text { Modified version have a better success rate than } \\
\text { original ABC }\end{array}$ & [53] \\
\hline 25 & $\begin{array}{l}\text { Changyou Zhenga, } \\
\text { Xiaoming Liua, Song } \\
\text { Huanga and Yi Yaoa }\end{array}$ & Ant Colony & $\begin{array}{l}\text { SYS1, SYS2, SYS3 from } \\
\text { Musa dataset }\end{array}$ & $\begin{array}{l}\text { Experiments with three typical models show that } \\
\text { this ant colony based algorithm demonstrates } \\
\text { good applicability }\end{array}$ & [55] \\
\hline 26 & $\begin{array}{l}\text { Latha Shanmugam } \\
\text { and Lilly Florence }\end{array}$ & Ant Colony & Musa real time data-set & $\begin{array}{l}\text { Based on the results, it was found that the } \\
\text { Enhanced Ant Colony Optimization Method is } \\
\text { giving better estimation accuracy than Existing } \\
\text { ACO method. Time and Space Complexity is } \\
\text { also reduced. }\end{array}$ & [57] \\
\hline 27 & The UK's expert & Ant Colony & $\begin{array}{l}\text { failure data which is given } \\
\text { in the Musa data Set from } \\
\text { the DACS Web Site }\end{array}$ & $\begin{array}{l}\text { Based on the results, we found that the proposed } \\
\text { Simulated Ant Colony Optimization Method is } \\
\text { giving } 15 \% \text { better estimation accuracy }\end{array}$ & \\
\hline 28 & $\begin{array}{l}\text { Najla Akram AL- } \\
\text { Saati }\end{array}$ & $\begin{array}{l}\text { Cuckoo } \\
\text { Search }\end{array}$ & $\begin{array}{l}\text { first group dataset: A } \\
\text { Sheta. Et al. (2006) } \\
\text { second group dataset: } \\
\text { John Musa of Bell } \\
\text { Telephone Laboratories }\end{array}$ & $\begin{array}{l}\text { CS do better than both PSO and ACO in finding } \\
\text { better parameters tested using identical datasets. }\end{array}$ & [65] \\
\hline 29 & $\begin{array}{l}\text { Nidhi Gupta and } \\
\text { Manu Pratap Singh }\end{array}$ & $\begin{array}{l}\text { Stimulated } \\
\text { Annealing }\end{array}$ & $\begin{array}{l}\text { a series of tests conducted } \\
\text { under certain stipulated } \\
\text { conditions on } 1,000 \\
\text { software components }\end{array}$ & $\begin{array}{l}\text { Results show that after applying the sequential } \\
\text { testing with MFA we can optimize the number of } \\
\text { failures up to a minimum value }\end{array}$ & {$[60]$} \\
\hline 30 & $\begin{array}{l}\text { Mohamed Benaddy } \\
\text { and Mohamed } \\
\text { Wakrim }\end{array}$ & $\begin{array}{l}\text { Stimulated } \\
\text { Annealing }\end{array}$ & $\begin{array}{l}\text { John Musa of Bell } \\
\text { Telephone Laboratories }\end{array}$ & $\begin{array}{l}\text { The performance in execution time of the } \\
\text { proposed adaptive simulated Annealing is better } \\
\text { than the RCGA, because of the search space, } \\
\text { which reduced from a population of solutions for } \\
\text { the RCGA to one solution for the proposed } \\
\text { Simulated Annealing }\end{array}$ & [62] \\
\hline
\end{tabular}




\begin{tabular}{|c|c|c|c|c|c|}
\hline 31 & $\begin{array}{c}\text { Kirti Tyagi and Arun } \\
\text { Sharma }\end{array}$ & Neuro Fuzzy & $\begin{array}{c}\text { collected data from 47 } \\
\text { classroom-based projects }\end{array}$ & $\begin{array}{c}\text { Results show that the ANFIS improves the } \\
\text { reliability evaluation of the FIS technique }\end{array}$ & [41] \\
\hline 32 & $\begin{array}{c}\text { M. Casertaa, and A. } \\
\text { Márquez Uribe }\end{array}$ & Tabu Search & Berman and Ashrafi (1993) & $\begin{array}{c}\text { Proposed algorithm is robust with respect to its } \\
\text { parameters and it is especially suited for very } \\
\text { large scale instances of the reliability problem. }\end{array}$ & [64] \\
\hline
\end{tabular}

In this summary, we notice that different soft computing techniques are used in different shapes for these models. We also observed that Neural Network approach is more liked by the researchers in software reliability models. Genetic Programming provides more accuracy than other soft computing techniques. Cuckoo Search, Stimulated Annealing and Tabu Search are used in this field but not so widely yet. This table data is important in case of comparison and selection of soft computing technique in terms of modeling capabilities.

\section{COMPARISON OF DIFFERENT SOFT COMPUTING TECHNIQUES IN TERMS OF MODELING CAPABILITIES}

Comparisons are very useful in case of optimal selection, user can view all possible choices on a single platform and select the best suited as his/her requirements. In Table No. 2 we compared different soft computing techniques in terms of software reliability modeling capabilities such as data sets, re-adjustments for new data set, process visibility, facts and outputs etc.

Table 2. Comparison of Soft Computing Techniques in terms of Modeling Capabilities

\begin{tabular}{|c|c|c|c|c|c|c|c|}
\hline Sr. No & $\begin{array}{c}\text { Technology } \\
\text { Used }\end{array}$ & $\begin{array}{l}\text { Explain } \\
\text { outputs }\end{array}$ & $\begin{array}{l}\text { Suitability } \\
\text { for small } \\
\text { data sets }\end{array}$ & $\begin{array}{c}\text { Can be } \\
\text { re-designed } \\
\text { for new } \\
\text { data set }\end{array}$ & $\begin{array}{l}\text { Reasoning } \\
\text { process is } \\
\text { visible }\end{array}$ & $\begin{array}{l}\text { Applicability } \\
\text { for complex } \\
\text { models }\end{array}$ & $\begin{array}{c}\text { Either } \\
\text { known } \\
\text { facts considered }\end{array}$ \\
\hline 1 & Neural Networks & No & No & No & No & Yes & Partially \\
\hline 2 & Fuzzy Logic & Yes & Yes & Yes & Yes & Yes & Yes \\
\hline 3 & Genetic Algorithms & Partially & Partially & Yes & Yes & Partially & No \\
\hline 4 & Genetic Programming & Yes & No & No & No & Yes & No \\
\hline 5 & Artificial Bee Colony & Yes & Partially & Partially & No & Yes & Yes \\
\hline 6 & Ant Colony & Yes & No & Yes & Yes & Yes & Yes \\
\hline 7 & Stimulted Anealing & Yes & No & Yes & Yes & Yes & Yes \\
\hline 8 & Tabu Search & No & Partially & Yes & Yes & Yes & Yes \\
\hline 9 & Cuckoo Search & Yes & No & Yes & Yes & Yes & Yes \\
\hline
\end{tabular}

This comparison has outlined some parameters of modeling capabilities. From this table we observed that all the techniques explain its outputs and are applicable for complex models except genetic algorithm. Comparison also revealed that only fuzzy Logic can be widely used for all the modeling capabilities. Ant colony, Stimulated Annealing, Tabu Search and Cuckoo Search can be used for most of the modeling capabilities except only small data set capabilities. The rapid growth of soft computing techniques suggests that the impact of these algorithms will be used increasingly for software reliability models in the coming years. This table will help computer scientist who are keen to contribute their works to the field of software reliability.

\section{CONCLUSION}

In this paper, we have discussed about the work done by the various researchers, with the endeavor made to include as many references as possible from year 1990 to 2014. Based on this paper, we thrash out some soft computing techniques, such as: Neural networks (NN), Fuzzy Logic (FL), Genetic Algorithm (GA), Genetic Programming (GP), Artificial Bee Colony (ABC) and Ant Colony etc. We emphasized on the role of existing soft computing techniques in software reliability modeling, with the reliance that it would serve as a reference to both old and new, incoming researchers in this field, to support their understanding of current trends and assist their future research prospects and directions. Further we compared soft computing techniques in terms of modeling capabilities, that enhances the selection process of soft computing technique for software reliability models.

\section{REFERENCES}

[1] K.K. Aggarwal, Yogesh Singh, "Software Engineering", New Age International publisher, New Delhi, 2005.

[2] Kapur, P.K. and Garg, R.B., "Cost reliability optimum release policies for a software system with testing effort", Operations Research, Vol. 27, No. 2, pp. 109-116, 1990.

[3] Musa J.D., "Software Reliability Engineering: More Reliable Software, Faster Development and Testing", McGraw-Hill, 1999.

[4] Musa, J.D., Iannino, A. and Komodo, K., "Software Reliability: Measurement, Prediction and Application", McGraw-Hill, 1987.

[5] P. Bonissone, Y-T Chen, K. Goebel, \& P. Khedkar, "Hybrid Soft Computing Systems: Industrial and Commercial Applications", Proceedings of the IEEE, 87(9): 1641-1667, September 1999.

[6] Santosh Kumar Das, Abhishek Kumar, Bappaditya Das and A.P.Burnwal, "On Soft computing Techniques in Various Areas”, ACER, pp. 59-68, CS \& IT-CSCP, 2013. 
[7] L. A. Zadeh, "Fuzzy Algorithms", Information and Control , Vol. 12, pp. 94-102, 1968.

[8] L. A. Zadeh, "Fuzzy Sets", Information and Control, Vol. 8, pp. 338-353, 1965.

[9] Kuo, W. \& Prasad, V. R., "An annotated Overview of System Reliability Optimization", IEEE Transaction on Reliability 49(2):176-186, 2000.

[10] Felix Streichert, "Introduction to Evolutionary Algorithms", Frankfurt MathFinance Workshop, university of Tubingen. Germany, April 2-4, 2002.

[11] Ajith Abraham, "Evolutionary Computation", Handbook of Measuring System Design, edited by Peter $\mathrm{H}$. Sydenham and Richard Thorn. John Wiley \& Sons, Ltd. ISBN: 0-470-02143-8. 2005.

[12] S. Boccaletti et al., "The control of chaos: theory and applications", Elsevier Science, 2000.

[13] Gaurav Aggarwal and Dr. V.K Gupta, "Neural Network Approach to Measure Reliability of Software Modules: A Review", in International Journal of Advances in Engineering Sciences Vol.3, Issue 2, April, 2013.

[14] N. Karunanithi , Y.K. Malaiya , D. Whitley, "Prediction of software reliability using neural networks", Proceedings of the Second IEEE International Symposium on Software Reliability Engineering, pp. 124-130, 1991.

[15] N. Karunanithi, D. Whitley, Y.K. Malaiya, "Using neural networks in reliability prediction", IEEE Software, Vol. 9, no. 4, pp.53-59, 1992.

[16] N. Karunanithi, D. Whitley, Y.K. Malaiya, "Prediction of software reliability using connectionist models", IEEE Trans Software Engg., Vol. 18, No. 7, pp. 563-573, 1992.

[17] T. M. Khoshgoftaar, R. M. Szabo, and P. J. Guasti, "Exploring the Behavior of Neural-network Software Quality Models," Software Eng. J., Vol. 10, No. 3, pp. 89-96, May 1995.

[18] R. Sitte, "Comparison of Software Reliability Growth Predictions: Neural networks vs. parametric recalibration", IEEE transactions on Reliability, pp. 285-291, 1999.

[19] K.Y. Cai , L. Cai , W.D. Wang, Z.Y. Yu, D. Zhang, “On the neural network approach in software reliability modeling", The Journal of Systems and Software, vol. 58, no. 1, pp. 47-62, 2001.

[20] S. L. Ho, M. Xie and T. N. Goh, "A Study of the Connectionist Models for Software Reliability Prediction", in Computers and Mathematics with Applications Vol. 46, pp. 1037-1045, 2003.

[21] L. Tian, A. Noore, "On-line prediction of software reliability using an evolutionary connectionist model", The Journal of Systems and Software, Vol. 77, no. 2, pp. 173-180, 2005.

[22] L. Tian, A. Noore, "Evolutionary neural network modeling for software cumulative failure time prediction", Reliability Engineering and System Safety, Vol. 87, no. 1, pp. 45-51, 2005.

[23] Yu Shen Su, Chin-Yu Huang, Yi Shin Chen and Jing Xun Chen, "An Artificial Neural-Network-Based Approach to Software Reliability Assessment", TENCON, IEEE Region 10, pp-1-6, 2005.

[24] S.P.K. Viswanath, "Software Reliability Prediction using Neural Networks", PhD. Thesis, Indian Institute of Technology Kharagpur, 2006.

[25] Q.P. Hu, Y.S. Dai, M. Xie, S.H. Ng, "Early software reliability prediction with extended ANN model", Proceedings of the 30th Annual International Computer Software and Applications Conference, pp. 234-239, 2006.

[26] Su, Y.-S., Huang, C.-Y., "Neural-network-based approaches for software reliability estimation using dynamic weighted combinational models", Journal of Systems and Software 80 (4), 606-615, 2006.

[27] Kanmani, S., Uthariaraj, V.R., Sankaranarayanan, V., Thambidurai, P., "Object-oriented software failure fault prediction using neural networks", Information and Software Technology, Vol. 49, 483-492, 2007.

[28] Sultan H. Aljahdali and Khalid A. Buragga, "Employing four ANNs Paradigms for Software Reliability Prediction: an Analytical Study", in ICGST-AIML Journal, ISSN: 1687-4846, Vol. 8, Issue II, 2008.

[29] Y. Singh, P. Kumar, "Application of feed-forward networks for software reliability prediction", ACM SIGSOFT Software Engineering Notes, Vol. 35, no. 5, pp. 1-6, 2010.

[30] Y. Singh, P. Kumar, "Redirection of Software Reliability Using feed Forward Neural Networks", International conference on Computational Intelligence and software Engineering, pp. 1-5, 2010.

[31] Nirvikar Katiyar and Raghuraj Singh, "Effect of Neural Network for Prediction of Software Reliability", in VSRD-IJCSIT, Vol. 1 (7), pp 490-500, 2011.

[32] C.Y. Huang, M.R. Lyu, "Estimation and Analysis of Some Generalized Multiple Change-Point Software Reliability Models", IEEE Transaction on Reliability, Vol. 60, no. 2, pp. 498-514, 2011.

[33] Manjubala Bisi and Neeraj Kumar Goyal, “ Software Reliability Prediction using Neural Network with Encoded Input", International Journal of Computer Applications (0975 - 8887) Vol. 47- No.22, 2012.

[34] Sandeep Kumar Jain and Manu Pratap Singh, "Estimation for Faults Prediction from Component Based Software Design using Feed Forward Neural Networks", IJARCCE, Vol. 2, Issue 7, 2013.

[35] Sultan Aljahdali and Narayan C. Debnath, “ Improved Software Reliability Prediction through Fuzzy Logic Modeling", IASSE , 17- 21, 2004.

[36] Cai, K.Y., Wen, C.Y., Zhang, M.L., "A critical review on software reliability modeling", Reliability Engineering and System Safety 32 (3), 357-371, 1991.

[37] Khalaf Khatatneh and Thaer Mustafa, "Software Reliability Modeling Using Soft Computing Technique", in European Journal of Scientific Research ISSN 1450216X Vol.26 No.1, pp.147-152, 2009.

[38] Reformat, M., "A fuzzy-based multimodel system for reasoning about the number of software defects", International Journal of Intelligent Systems 20 (11), 1093-1115, 2005.

[39] Sultan Aljahdali, "Development of Software Reliability Growth Models for Industrial Applications Using Fuzzy Logic”, Journal of Computer Science 7 (10): 1574-1580, 2011.

[40] S. Chatterjee, S. Nigam, J.B. Singh, L.N. Upadhyaya, "Application of Fuzzy Time Series in Prediction of Time Between Failures \& Faults in Software Reliability Assessment”, in Fuzzy Inf. Eng. 3: 293-309, 2011.

[41] Kirti Tyagi and Arun Sharma, "An adaptive neuro fuzzy model for estimating the reliability of component-based software systems", Applied Computing and Informatics, 2014.

[42] L. Tian and A. Noore, "Evolutionary neural network modeling for software cumulative failure time prediction", Reliability Engineering \&amp; System Safety, Vol. 87, no. 1 , pp. $45-51,2005$.

[43] L. Tian and A. Noore., "On-line prediction of software reliability using an evolutionary connectionist model", Journal of Systems and Software, Vol. 77, no. 2, pp. 173 $-180,2005$. 
[44] Sultan H. Aljahdali and Mohammed E. El-Telbany, "Genetic Algorithms for Optimizing Ensemble of Models in Software Reliability Prediction", in ICGST-AIML Journal, Vol. 8, Issue I, June 2008.

[45] Sultan H. Aljahdali and Mohammed E. El- telbany, "Software Reliability Prediction Using Multi-Objective Genetic Algorithm", 978-1-4244-3806-8/09/\$25.00, IEEE, 2009.

[46] R.SatyaPrasad, O.NagaRaju and R.R.LKantam, "SRGM with Imperfect Debugging by Genetic Algorithms", in International Journal of software engineering \& applications (IJSEA), Vol. 11, No. 2, April 2010.

[47] E. Costa, S. Vergilio, A. Pozo, and G. Souza. Modeling software reliability growth with genetic programming. In ISSRE '05: Proceedings of the 16th IEEE International Symposium on Software Reliability Engineering, Washington, USA, IEEE Computer Society, 2005.

[48] E. Oliveira, A. Pozo, and S. Vergilio, "Using boosting techniques to improve software reliability models based on genetic programming", in ICTAI '06: Proceedings of the 18th IEEE International Conference on Tools with Artificial Intelligence, Washington, USA, IEEE Computer Society, 2006.

[49] Y. Zhang and H. Chen. Predicting for MTBF failure data series of software reliability by genetic programming algorithm. In Proceedings of the Sixth International Conference on Intelligent Systems Design and Applications, Washington, USA, IEEE Computer Society, 2006.

[50] Wasif Afzal and Richard Torkar, "Suitability of genetic programming for software reliability growth modeling", International Symposium on Computer Science and its Applications, 978-0-7695-3428-2/08 \$25.00, IEEE, 2008.

[51] Eduardo Oliveira Costa, Aurora Trinidad Ramirez Pozo, and Silvia Regina Vergilio, "A Genetic Programming Approach for Software Reliability Modeling”, IEEE Transactions on Reliability, Vol. 59, NO. 1, March 2010.

[52] Zainab Al-Rahamneh, Mohammad Reyalat, Alaa F. Sheta, Sulieman Bani-Ahmad, Saleh Al-Oqeili, " A New Software Reliability Growth Model:GeneticProgramming-Based approach", Journal of Software Engineering and Applications, 4, pp. 476-481, 2011.

[53] Tarun Kumar Sharma, Millie Pant and Ajith Abraham, "Dichotomous Search in $\mathrm{ABC}$ and its Application in Parameter Estimation of Software Reliability Growth Models", 978-1-4577-1124-4/11/\$26.00_c IEEE, 2011.

[54] Li, W., Q. Yin and X. Zhang, "Continuous quantum ant colony optimization and its application to optimization and analysis of induction motor structure", Proceedings of the IEEE 5th International Conference on Bio-Inspired Computing: Theories and Applications, Sep. 23-26, IEEE Xplroe Press, Changsha, pp: 313-317. DOI: 10.1109/BICTA. .5645311, 2010.

[55] Changyou Zhenga, Xiaoming Liua, Song Huanga and Yi Yaoa, "A Parameter Estimation Method for Software Reliability Models", in Elsevier Ltd. Selection, 2011.

[56] Latha Shanmugam1 and Dr. Lilly Florence, "A Comparison of Parameter best Estimation Method for software reliability models", International Journal of Software Engineering \& Applications (IJSEA), Vol. 3, No.5, 2012.

[57] Latha Shanmugam and Lilly Florence, "Enhancement and comparison of ant colony optimization for software reliability models", Journal of Computer Science 9 (9): pp 1232-1240, 2013.
[58] Kirkpatrick Jr., S., Gelatt, C., Vecchi, M. "Optimization by simulated annealing”, Science, 220 (4598), 498-516, 1983.

[59] Cerny, V., "Thermodynamical approach to the traveling salesman problem: an efficient simulation algorithm", Journal of Optimization Theory and Application, 45 (1), pp. 41-51, 1985.

[60] Nidhi Gupta and Manu Pratap Singh, "Evolutionary algorithms, simulated annealing and tabu search: a comparative study", IJE Transactions B: Applications, Vol. 19, No. 1, 2006.

[61] Pai, P.F., Hong, W.C., "Software reliability forecasting by support vector machines with simulated vector machines with simulated annealing algorithms", The Journal of Systems and Software 79, 747-755, 2006.

[62] Mohamed Benaddy and Mohamed Wakrim, "Simulated Annealing Neural Network for Software Failure Prediction", International Journal of Software Engineering and Its Applications, Vol. 6, No. 4, 2012.

[63] Glover, F., Laguna, M. "Tabu Search", Kluwer Academic Publishers, Boston, 1997.

[64] M. Caserta and A. Márquez Uribe, "Tabu search-based meta-heuristic algorithm for software system reliability problems", 0305-0548/\$, Elsevier Ltd, 2006.

[65] Najla Akram AL-Saati and Marwa Abd-AlKareem, "The Use of Cuckoo Search in Estimating the Parameters of Software Reliability Growth Models", (IJCSIS) International Journal of Computer Science and Information Security, Vol. 11, No. 6, 2013.

[66] Sona Ahuja, Guru Saran Mishra and Agam Prasad Tyagi, "Jelinski - Moranda Model for Software Reliability Prediction and its G. A. based Optimised Simulation Trajectory”, D. E. I. Dayalbagh, Agra, pp. 399-404, 2002.

\section{Authors' Profile}

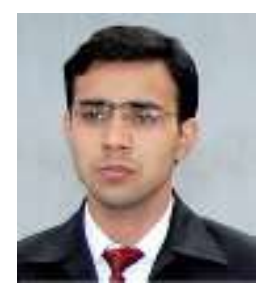

Kuldeep Singh Kaswan: was born in Haryana, India in 1982. He is pursuing a Doctors Degree in Computer Science under the faculty of Computer Science at Banasthali Vidyapith, Rajasthan. He has obtained his Master Degree in Computer Science and Engineering from Choudhary Devi Lal University, Sirsa (Haryana) and Bachelor Degree from Kurukshetra University, Kurukshetra (Haryana). His area of interests includes software engineering and reliability.

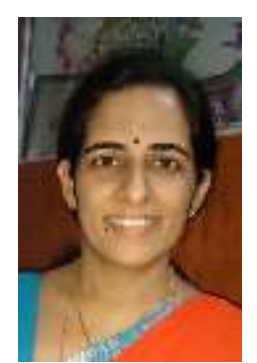

Sunita Choudhary was born in Rajasthan, India in 1978. She received Doctors Degree in Computer Science under the Faculty of Computer Science at the Banasthali University (Rajasthan), India. She has obtained his Bachelor of Science in Computer Science and Master of Computer Application Degrees from Banasthali University in 1999, and 2001 respectively. Presently, she is working as an associate professor in Department of Computer Science at Banasthali University, Rajasthan, India. Her research interests include Algorithms and Distributed Computing.

Kapil Sharma was born in Haryana, India in 1977. He received Doctors Degree in Computer Science and Engineering under the Faculty of Engineering and Technology at the M. D. 


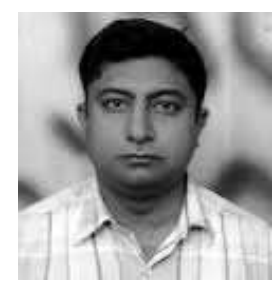

University, Rohtak (Haryana), India. He has obtained his Bachelor of Engineering and Master of Technology Degrees in Computer Science \& Engineering and Information Technology from M. D. University, Rohtak, and IASE, Rajasthan, India in 2000, and 2005 respectively. Presently, he is working as an associate professor in Department of Computer Science at Delhi Technological University, Delhi, India. His research interests include software engineering, and reliability.

How to cite this paper: Kuldeep Singh Kaswan, Sunita Choudhary, Kapil Sharma,"Software Reliability Modeling using Soft Computing Techniques: Critical Review", International Journal of Information Technology and Computer Science(IJITCS), vol.7, no.7, pp.90-101, 2015. DOI: 10.5815/ijitcs.2015.07.10 